\title{
YABANCI GÖZÜYLE ATATÜRK
}

\author{
Prof. Dr. Ziya BURSALIOĞLU
}

Atatürk'ün reformlarını ve onların önemini kavrayabilmek için, bu reformların ülke dışında yarattığı etkilerin derinliğine bir incelemesini yapmak ve batılı yazarlarca reformcunun nasıl değerlendirildiğini bilmek gerekir. İzleyen satırların amacı, böyle ulusal ve uluslararası bir liderin liderlik anatomisini, etkileme gücünün derecesini, olağanüstü özelliklerini, idealizmini ve halkının ona beslediği sevgiyi bu yazarların yorumlarından öğrenmektir (1).

En büyük batılılaştırıcı olmasına ve ülkesini boydan boya süratle batılılaştırmasına rağmen, bazı batılıların Atatürk'ü dışlaması mantığa aykırıdır. $(2,3)$. Ülkesini batılılaştırmak için, batı ile savaşmak zorunda kalması „da, diğer bir çelişki sayılabilir. Asyayı fetheden yenilmez batıyı durdurması ve emperyalist çıkarlara engel olması, az da olsa, böyle değerlendirmelerin altında yatan temel nedenlerdir $(4,5)$. Fakat; hem kendisi hem de reformları batılı çevrelerde tartış1maz gerçekler olarak yer aldıkça, bu uluslararası ilgi, her ikisinin de bilimsel nitelik kazandığını kanıtladı (6). Ancak Atatürk'ün doğabileceği bir ortam çoğu batılılara yabancı olmasına rağmen, Türkiye'yi ziyaret eden yabancilar kendilerini onun huzurunda ve ondan etkilenmiş gibi hissederler $(7,8)$. Bu nedenle, modern Türkiye, kişiliğini bütün ülkeye mühürlemiş olan yaratıcısına değinilmeden düşünülemez ve tartışılamaz (9). Yapılması olanaksız görülen bir devrimi başarmış olmasından dolayı, çağının en büyük devlet adamı olarak kabul edilmeye hak kazandığı gibi, bir ulusu yeniden modelleştiren yegâne sanatkar olarak kalmaya devam etmektedir (10). Yakın Doğuda görülmemiş olan radikal bir zihniyet, sağduyu ve tutarlılık ile; yeni Türkiye'de rönesansın sembolu olmuştur (11). Onun reformları, yalnız davranışta değil düşünce sisteminde de, Türk toplumunun derinliğine yerleşti. Atatürk hâlâ Türkiye'de devam eden topyekün ve sürekli yenileşmenin arkasındaki itici ruh gibidir (12). Atatürk'te büyüklüğün gerçek öğelerinin bulunduğu tartışılamaz (13). Halkının kaybol- 
muş atılımını ve en iyi geleneğini enerjik varlığında kişileştirdi (14). Bir ulusun geleneklerini gözardı edebilecek olağanüstü, nitelikler ve cesarete sahip bulunuyordu (15).

Atatürk soğukkanlı ve profesyonel tavırlı bir askerdi. Çekingen ve az konuşan, çelik gri gözlerinin arkasında düşünceli olan, sorumluluktan zevk alan bir muharebe meydan lideri, en ters durumlarda en iyisini başaran muhteşem bir generaldi (16). Atatürk'ün askeri bir deha sahibi olduğu kuşku götürmez. Bu deha, kişisel cesaret, olayları ve davranışları tahmin yeteneği, yüksek derecede etkilemenin gerektirdiği sabır ve içgörüş, farklı alternatifleri aldatacak hareket yeteneği ve karşı güçleri yansız olarak değerlendirme yeteneğinden oluşuyordu. Kendi içindeki çelişki, otoriter eğilimleri kapsayan üstün özgürlüğünden ileri geliyordu. Sokaktaki adamdan başka hiç kimseye yakınlık göstermemesine rağmen, ona tereddütsüz inanan sadık bir grup subaylar ve dostlar edinebilmiş olması da, diğer bir paradoks oluşturmuştu. (17) Şan ve şöhreti küçümser, dalkavuluktan hoşlanmazdı; çünkü zevklerinde tamamen batılıydı (18).

Atatürk, reformlarını özgürlüğe doğru disiplinli bir yürüyüşle ve bir matematikçinin soğuk mantığı ile başardı (19). Her reform için uygun zamanı bekleyerek, aşamalarla ilerledi. En uygun psikolojik atmosferi bulma yeteneği ve ılımlı davranışı, onun başlıca güçleri olmuştur (20). Zafere ulaştığı anda, ona daha çok şöhret ve ihtiras getirebilecek, çekici fırsatlardan kaçınmasını bildi (21). Reformların yayılmasında, kendi inandırıcı güçlerine ve kişisel karizmasına güvendi $(22,23)$. Halk iradesinin desteğini kazanan ve inanılmaz bir reform çabası olan Atatürk, muhakeme ve takdir yeteneği, sarsılmaz kararlılığı, vatanseverlik ihtirası ve tartışılmaz kişisel magnetizması olan bir liderdi (24).

Atatürk, hızlı geçiş döneminde olan yeni bir toplumda, karizmatık liderliğin- daha doğrusu her türlü liderliğin- en güzel örneklerini verdi (25). Bir liderin tükenmez enerjisine, devlet adamlığının yeteneklerine ve tarihe biçim veren bağımsız eğilimlere sahipti (26). Onun parlak ve ilham yerici liderliği; bir hareketi, bir orduyu ve bir ulusu yenilemekle başladı. Fakat gerçek büyüklüğü, toplumun ve kültürün yapisında yaptığı reformlarda örnek olma liderliğinde görülür (27).

Atatürk sembolü, bütün Asya için bir ilham kaynağı olmuştur, çünkü Orta Doğu ve Asya'da, söndürülemeyen ulusçuluk ateşleri 
tutuşturmuştur $(28,29)$. O, sosyal sembolizma üstadı olarak, modern Türkiye'yi yaratan ve besleyen, yeni bir ruhun vücut buluşu gibiydi (30). Bütün reformlarda, kendisi örnek olarak, halkın muhayyelesini eyleme geçirdi (31). Ününün büyük bir kısmı, sosyal değişimler mucizesinde göstermiş olduğu ihtilalci liderlikten kaynaklanır (32). Önemsedikleri gelenekleri ortadan kaldırdığı zaman bile, halk liderinin peşinden gitti, çünkü onlara daha önce kendilerinden esirgenen ulusal duygular kazandırmıştı (33).

Herşeyin üstünde, Atatürk büyük bir inanç sahibiydi ki, bu halkının muhteşem geleceğine olan inancıydı (34). Bu nedenle, Orta Doğuda halka giden ve onların sıcak sevgisi. ve saygısını kazanan ilk modern devlet adamı olmuştur $(35,36)$. Halkçılık onun politik felsefesinin bir parçasıydı ve bir reformcu olarak, halka teması hiç betmedi (37). Asıl gücünü, onun hizmetlerini minnetle anan ve onu kutsallaştıran halktan aldı ki, bu durum halkın onun ilkelerini benimseme ve uygulama isteğini açıklamaktadır (38). Onun büyük liderlik güçleri, Türklerin parlak kaderine olan fanatik inancı, özellikle bu inancın boşa çıkmamış oluşu; görevini gerçekleştirmede yararlandığı kişisel güdülerdir (39).

Atatürk'ün felsefesi olan Kemalizm hızlı kalkınmaya giden yolu keşfetti ve disiplinli bir eğitimle, bir kuşakta halkçı bir uygarlık sağlanabileceğini kanıtladı (40). Türkiye'nin yenileşmesi onunla başlar, buna o cesaret etti ve bunu o gerçekleştirdi (41). Atatürk eski kurumları kaldırıp yenilerini yaratan, tabuları yıkıcı büyük bir idealistti (42). Kaderciliğin meziyet ve ilericiliğin aykırılık olduğu doğuda, ihtilâlci bir mucize yaratmıştı (43). Onun asıl kahramanlığı, ülkesini dinselbir ortaçağ toplumundan, modern bir ulusal topluma dönüştürmesi olmuştur. (44) Türklerin yeni bir kimlik arayışının sonucu, Türkiyeyi doğu ile batı arasında bir ikilemden kurtaran kemalizm olmuştur (45). İnanılmaz Atatürk, bugün hayattan daha büyüktür. Bir yüzyıl sonra, daha da büyümesi kaçınılmazdır. Modern Türkiye'nin alt üstündeki büyük adamının hayalete benzer gölgesi, ulusuna semavi bir kehanetle rehberlik etmektedir (46).

Dünyaca kabul edilmiş büyük bir liderin, kendi ülkesinde çeşitli eleştirilere ve saldırılara uğraması, kuşkusuz ibret vericidir. Bu tür eylemlerin, komşu ülkelerin liderlerini gözümüzde büyütmemize ve onlardan gereksiz derecede etkilenmemize yol açtığı da bir gerçektir. Periyodik müdahalelere dayalı hatalı stratejiler, Atatürk ilkelerinin 
sağdan soldan kemirilmesini de önleyememiştir. Bugün onlara, her zamankinden daha sıkı sarılmak zorunda olduğumuzu tekrar hatırlamalıyı.

\section{KAYNAKLAR}

1. Bursalığiu, Sabit Ziyaettin. The Changing Character of Education in Successive Reformation Periods of Turkish History, Ph. D. Thesis, University of Illinois, Urbana, Illinois, 1965.

2. Rondot, Pierre. The Changing Patterns of the Middle East, Frederick A. Prager, New York, p. 85.

3. Rustow, Dankwart A. Politics and Westernization in the Near East, Princeton University, New Jersey, 1956, p. 25.

4. Lewis, Bernard., The Middle East and the West, Indiana University Press, Bloomington, 1964, p. 107.

5. Robinson, Richard D.,The First Turkisth Republic, Harvard University Press, Cambridge, 1963, p. 90.

6. Melzig, Herbert., Atatürk, Etude Bibliographique, Ankara, 1947, p. 5.

7. Wortham. H.E., Mustafa Kemal of Turkey, Little Brown and Company, Boston, 1961, p. 11.

8. Tobin, Chester M., Turkey, Key to East, Putnam's Sons, New York, 1944, p. 121.

9. Allison, Grace., Turkey Today, Hutchinson and Company, London, 1928, p. 15.

10. Hall, Joseph Washington., Eminents Asians, Appleton and Company, New York, 1930, p. 252.

11. Price, M. Philips., A History of Turkey, George Allen and Unwin, London, 1946, p. 103.

12. Robinson, Richard D., The First Turkish Republic, Harvard University Press, Cambridge, 1963, p. 92.

13. Chirol, Valentine., The Occident and the Orient. University of Chicago, 1924, p. 64.

14. King, William B., The Balkans, McMillan Company, New York, 1945 , p. 206 , 
15. Garnett, Lucy., Home Life in Turkey, McMillan Company, New York, 1909, p. 83.

16. Ward, Robert A., and Rustow, Dunkward A., Political Modernization in Japan and Turkey, Princeton University Press, Prínceton, 1964, p. 375.

17. Robinson, Richard D., The First Turkish Republic. Harvard University Press, Cambridge, 1963, p. 30-32.

18. Wortham, H.E., Mustafa Kemal of Turkey, Little Brown and Company, Boston, 1931, p. 3.

19. Froembgen, Hanns. Kemal Atatürk, Hillman Curl, New York, 1937, p. 257.

20. Peters, Richard., The Dtory of the Turks, C.S. Publishing Company, New York, 1959, p. 185.

21. Lewis, Bernard., The Emergence of Modern Turkey, Oxford University Press, London, 1961, p. 268.

22. Ostrog, Count Lenon., The Angora Reform, University of London Press, London, 1927, p. 93.

23. Lengyel, Emil., Turkey, Random House, New York, 1941, p. 418.

24. Toynbee, Arnold J., and Kirkwood, K.P., Turkey, Charles Ccribncr's Sons, New York, 1927, p. 131, 191.

25. Rustow, Dankwart A., Politics and Westernization in the Near East, Princieton University, New Jersey, 1956, p. 29.

26. Kohn, Hans., Western Civilization in the Near East, Columbia University Press, New York, p. 246, 1936.

27. Lewis, Bernard., The Emergence of Modern Turkey, Oxford University Press, London, 1961, p. 287.

28. Wortham, H.E., Mustafa Kemal of Turkey, Little Brown and Company, Boston, 1931, p. 232.

29. Brock, Ray., Ghost on Horseback: The Incredible Atatürk, New York, Duell Sloan and Pearce, 1954, p. 5.

30. Tobin, Chester M., Turkey, Key to the East, Putnam's Sons, New York, 1944, p. 121.

31. Allen, Henry Elisha., The Turkish Transformation, Universit yof Chicago Press, Chicago, 1935, p. 128. 
32. Webster, Donald Everett., The Turkey of Atatürk, American Academy of Political and Social Science, Philadelphia, 1959, p. 146.

33. Luke, Sir Haryy., The Making of Modern Turkey, McMillan, London, 1936, p. 232.

34. Armstrong, H.C., Grey Wolf, Mustafa Kemal, Methuen, London, 1947, p. 248.

35. Humbaraci, Arslan, Middle Eeast Indictment, Robert Hale Limited, London, 1958, p. 35.

36. King, William B. The Balkans, McMillan Company, New York, 1945, p. 217.

37. Peters, Richard., The Story of the Turks, C.G. Publishing Company, New York, 1959, p. 185.

38. Allen, Herry Elisha., The Turkish Transformation, University of Chicago Press, Chicago, 1935, p. 46.

39. Lewis, Geoffrey., Turkey, FrederickA. Praeger, New York, 1960, p. 110.

40. Tongas, Gerard., Atatürk, Et le Vrai Visage de la Turquie, Librarie Orientaliste, Paris, 1937, p. 29.

41. Melia Jean., Mustafa Kemal, La Renovation de la Turquie, Paris, Charpentier, 1929, p. 110.

42. Wortham, H.E., Mustafa Kemal of Turkey, Little Brown and Company, Boston, 1931, p. 4.

43. Lengyel, Emil., Turkey, Random Rouse, New York, 1941. p. 9.

44. Hall, Joseph Washinton., Eminent Asians, Appleton and Company, New York, 1930, p. 295.

45. Eren, Nuri., Turkey Today and Tomorrow, Frederick A. Preaeger, New York, 1963, p. 19.

46. Brock, Ray., Ghoston Horseback: The Incredihle Atatürk, New York, Duell Sloan and Pearce, 1954, p. 6. 